\title{
Geometric Thinking of Malaysian Elementary School Students
}

\author{
Aida Suraya MdYunus
}

Prof., Corresponding author, Universiti Putra Malaysia, Malaysia, aida@upm.edu.my

\author{
Ahmad Fauzi Mohd Ayub \\ Universiti Putra Malaysia, Malaysia,afmy@upm.edu.my \\ Tan Tong Hock \\ Universiti Putra Malaysia, Malaysia, kenny7028@gmail.com
}

\begin{abstract}
Geometry is one of the basic skills to be mastered in Malaysian mathematics education. However, there is not much information on geometry attainment of the elementary school students based on van Hiele's levels. The purpose of this study was to determine the van Hiele's levels of geometric thinking among the elementary school learners. Three different instructional strategies based on modules were tested on three groups of students ;(i) van Hiele's phases of learning (VH-PL) module that guides students through the van Hiele's learning process, (ii) van Hiele's theory which is integrated with the Google SketchUp software (VHGSU) module and (iii) use of conventional instruction (NVH-CI) module which refers to teaching strategy without the use of van Hiele's theory of learning or any software in the teaching. This true experimental study involved 96 Year Five students of a Malaysian public school. Data were collected using Wu's Geometry Test (WGT) and sample responses identified by Fuys, Geddes, and Tischler (1988). Results showed that at the onset of the experiment, the students were operating at the lower levels of van Hiele's levels of geometric thinking. After the intervention, results of the WGT showed that most of the students in all three groups achieved a higher level of van Hiele's geometric thinking.
\end{abstract}

Keywords: geometry, van Hiele's levels of geometric thinking, van Hiele's phases of learning, Wu's geometry test, geometric thinking

\section{INTRODUCTION}

The van Hiele's geometric thinking theory is applied in the teaching of geometry in the elementary level in a number of countries. One of these countries is Taiwan. The teaching of geometry in Taiwan is designed and developed based on van Hiele's model of geometric thinking (Ministry of Education Taiwan, 1993, 2000, 2003). In Taiwan, the students have consistently showed good performance in mathematics especially in

Citation: Md. Yunus, A. S., Mohd Ayub, A. F., \& Hock, T. T. (2019). Geometric Thinking of Malaysian Elementary School Students. International Journal of Instruction, 12(1), 1095-1112. https://doi.org/10.29333/iji.2019.12170a 
the Trends in Mathematics and Science Study (TIMSS) with mean score consistently greater than the international benchmark. In addition, the ranking of the 8th grader is always in the top five of all participating countries (Wong, 2014).

In Malaysia, geometry is formally introduced early in the elementary school (Ministry of Education Malaysia, 2010) since it is a basic skill to be mastered. However, the teaching of geometry in Malaysia is not based on van Hiele's geometric thinking theory. According to Abdul Halim (2013); Mohd Salleh et al. (2012), by the end of their learning session, elementary students in Malaysia had not acquired the targeted learning outcomes in elementary mathematics which is equivalent to Level 2 (Informal Deduction) based on van Hiele's theory. This may be the reason why students in Malaysia faced more learning difficulties at the secondary level as the learning outcomes emphasise higher levels of attainment (L3- Deduction and L4- Rigor) based on van Hiele's geometirc thinking theory. It had been reported that the teaching and learning of mathematics in Malaysia has been too teacher-centred and students are not given enough opportunities to develop their own thinking (Abdul Halim \& Effandi, 2013; Noraini, 2005; 2007). Therefore, learning difficulties encountered in geometry may be attributed by inadequate experience provided to students.

The van Hiele's model of geometric thinking was first proposed in 1957 by Dina van Hiele-Geldof and Pierre van Hiele at the University of Utrecht in the Netherlands. Many mathematics educators associate the development of geometric thinking with van Hiele's model (Abdul Halim \& Effandi, 2013; Fuys et al., 1988; Mason, 1998; Noraini, 1998; 2007; Škrbec \&. Čadež, 2015; Usiskin, 1982; Wu \& Ma, 2005; 2015). However, most of these researchers had studied on the geometric thinking of students at secondary school levels. Considering the lack of evidence for elementary school learners, this study was aimed at identifying geometric thinking at the elementary school level. Attainment of concepts at the elementary level is of utmost importance since it becomes the foundation in the transition to further learning at the secondary level.

The purpose of this study was to determine the van Hiele's levels of geometric thinking of Malaysian elementary school learners by comparing their attainment using three different instructional strategies. Firstly, the use of van Hiele's phases of learning (VHPL) module that guides students through the van Hiele's learning process (information, guided orientation, explication, free orientation and integration) in order to progress through the levels of van Hiele's geometric thinking. Secondly, the use of van Hiele's theory which is integrated with the Google SketchUp software (VH-GSU) module that comprises of activities such as planning, delivery, and evaluation which are effectively disseminated in accordance with van Hiele's first three levels of geometric thinking and based on constructivist learning theory. Thirdly, the Conventional Instruction (NVH-CI) module which refers to teaching strategy without the use of van Hiele's theory of learning or any software in the teaching.

Specifically, the objectives of this paper are as follows: 
a) To determine the van Hiele's levels of geometric thinking among students using the three different instructional strategies; Google SketchUp (VH-GSU), van Hiele's Phases Learning (VH-PL) and the conventional instruction (NVH-CI);

b) To compare the effect of the instructional strategies on the students' attainment based on van Hiele's levels in the learning of geometry; and

c) To determine whether there is consistency in performance based on van Hiele's levels of geometric thinking in the pre-test, post-test and retention test between students using the three different instructional strategies (VH-GSU, VH-PL and $\mathrm{NVH}-\mathrm{CI}$ ) in the learning of geometry.

\section{Theoretical Framework}

Pierre van Hiele and Dina van Hiele-Geldof did their research in the late 1950s on the development of thought and concept in geometry amongst school children. The van Hiele's theory suggests that students' progress through numerous levels of geometric thinking, from merely recognizing geometry shapes to constructing a formal geometry proof (van Hiele, 1986; van Hiele, 1999). The theory enables us to explain why many students encounter difficulties in their geometry lessons. The theory also offers educators a teaching model to apply and practice in order to promote their students' levels of geometric thinking (Fuys et al., 1988; van Hiele, 1986).

The van Hiele's theory originally posited five sequential and hierarchical discrete levels of geometric thinking (Senk, 1989; Usiskin, 1982). Two different numbering schemes commonly used in the literature are as follows: Level 0 (L0) through to Level 4 (L4) and Level 1 (L1) through to Level 5 (L5) (Senk, 1989). The original numbering scheme used by van Hiele was Level 0 (L0) through to Level 4 (L4) which refers to Recognition/Visualisation, Analysis, Informal Deduction, Deduction and Rigor.

The focus of this study was only on the first three levels of van Hiele's learning phases because researches have shown that the first three levels (i.e. Level 0 (L0), Level 1 (L1) and Level 2 (L2)) play much more important roles in producing better conceptual understanding of elementary geometry in Malaysia (Mohd.Salleh et al., 2012, Chew \& Lim, 2013). At the Recognition/Visualisation Level (L0), students reason experimentally. Then, they establish properties of shapes by observing, measuring, drawing and making models. They identify shapes not as visual wholes but by their properties. For example, a student might think of a rhombus as a figure with four equal sides. At the Analysis Level (L1), the students can identify properties of figures. Students can recognise and name properties of geometric figures, but they do not yet understand the relationships between these properties and between different figures (e.g.: Rectangles have four right angles). At the Informal Deduction Level (L2), students are able to reason logically. They can form abstract definitions, distinguish between necessary and sufficient conditions for a concept and understand and, sometimes, even present logical arguments. They can classify figures hierarchically by analysing their properties and giving informal arguments to justify their classifications (e.g., identifying a square as a rhombus because "it's a rhombus with some extra properties") (Usiskin, 1982) 
Nolan and Swart (2015) indicated that educational technology may be used to supplement traditional approaches to help the students. Noraini (2007) showed that there are significant differences between the control (traditional approach) and experimental (using Geometer's Sketchpad) groups with the students in the experimental group doing much better and it was found that the geometric thinking was in line with van Hiele's theory. Wu and Ma (2010) used the Grey relational analysis (GRA) to analyze the WuMa Test of the van Hiele's levels of geometric thinking. Results showed that the Wu-Ma Test is a good instrument to measure the geometrical concepts according to van Hiele's levels of geometric thinking. Based on their research findings, Abdul Halim and Effandi (2013) suggested that activities in geometry for elementary students can be implemented using van Hiele's phases of learning geometry. The results showed that the developed activities were well-arranged based on van Hiele's phases of learning geometry with the assistance of Geometer's Sketchpad. Neslihan and Mehmet (2012) investigated the development of pre-service elementary mathematics teachers' geometric thinking levels using pre-test and post-test. The results of this study revealed the need of assessment on the development of pre-service elementary mathematics teachers through their geometric thinking levels.

In this study, van Hiele's levels of geometric thinking using Google SketchUp (VHGSU) module and van Hiele's phases learning (VH-PL) module were developed through carefully designed learning activities to assist students in progressing through the first three levels of van Hiele's levels of geometric thinking. The modules were designed and developed according to the ADDIE model (analysis, design, development, implementation and evaluation). The modules consisted of four sub-units, namely Unit 1 (Three Dimensional Shapes), Unit 2 (Triangles), Unit 3 (Squares and Rectangles) and Unit 4 (Cubes and Cuboids). For each unit, students were required to complete specific tasks in order to assist them to progress from their current level to a higher level as described in van Hiele's levels of geometric thinking.

Figure 1 shows the theoretical framework of this study. Phase I involved the analysis of essential information. The learning needs of the modules were determined based on the Malaysian elementary mathematics syllabus (Year 1 to Year 6), preliminary investigation pertaining to students' van Hiele's levels of geometry thinking using Qmethodology and discussion with mathematics teachers. Q-methodology was a research method used in psychology and in social sciences to study people's "subjectivity", that is, their viewpoint. It gathered data from an individual on multiple issues of interest. The individual's opinions were then clustered based on similarity of opinion. Therefore, the researcher was able to justify the learning objectives and items to be developed based on the results obtained. The purpose of Q-methodology was to determine whether the various opinions of the individual gave rise to a greater thematic understanding of the issues at hand (Brown, 2004). Interviews and discussions with mathematics teachers and experts were conducted to determine students' achievement in geometry and the theory underpinning the teaching of geometry. 

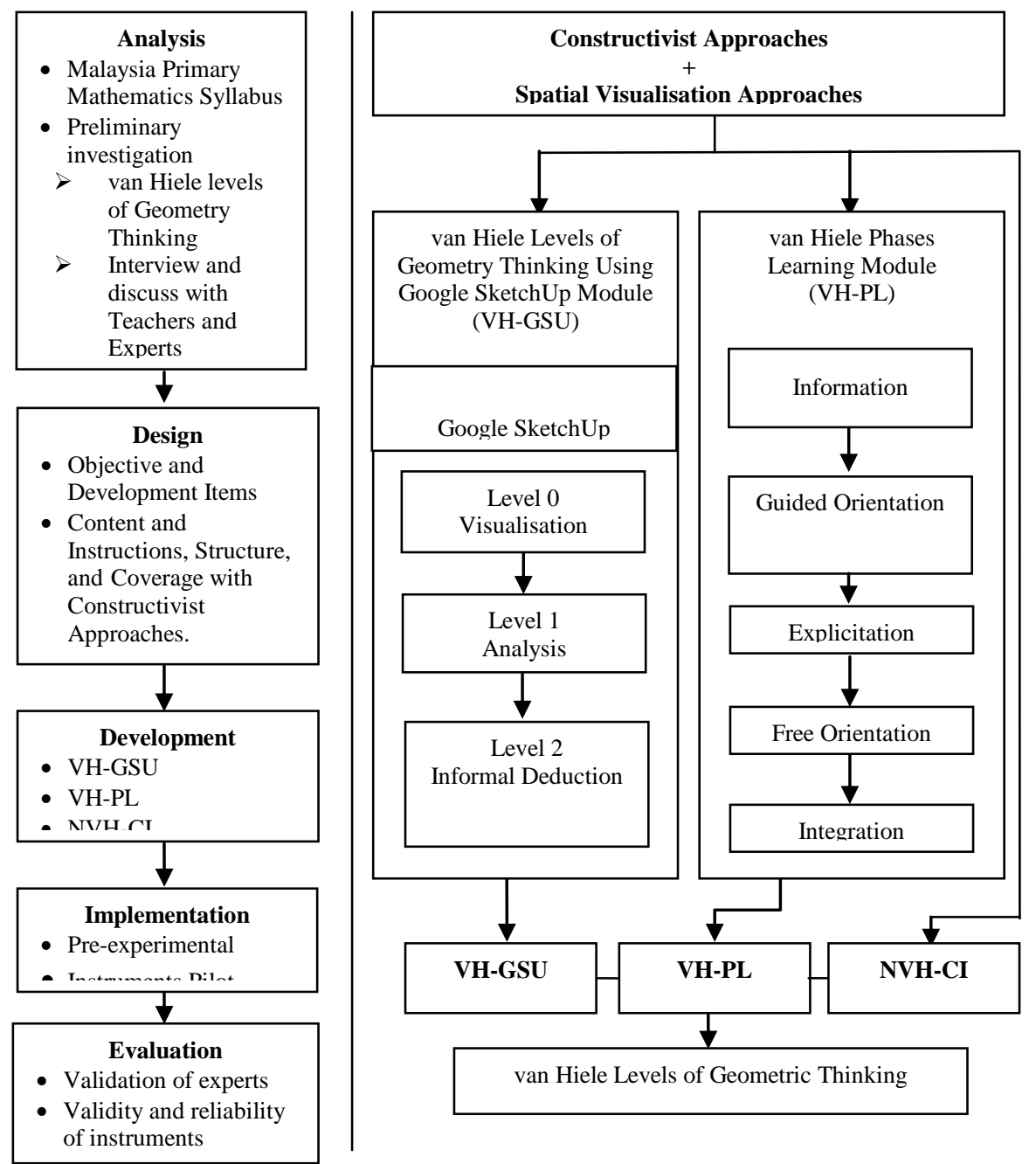

Figure 1

Theoretical Framework of the Study

In Phase II, determination of the design of the learning modules included identification of van Hiele's levels of geometric thinking to be addressed; design of content and instructions, structure arrangement in modules, coverage of the content; design of constructivist learning approaches for each learning module, design of visualisationoriented learning activities for van Hiele's Phases Learning Module and van Hiele's Levels of Geometric Thinking using Google SketchUp Module. The focus was on van Hiele's levels of geometric thinking, learning strategies and activities as shown in Table 1 and Table 2. 
Table 1

van Hiele's Phases of Learning

\begin{tabular}{ll}
\hline Phase & Description \\
\hline Information & Interaction between teacher and students through discussion. \\
Guided Orientation & Students learn geometry in exploration using guided activity. \\
Explication & Students can explain and express their views about the geometric structures observed. \\
Free Orientation & $\begin{array}{l}\text { Students are given more complex tasks which involve many steps and can be completed } \\
\text { through a variety of ways and through open-ended questions. }\end{array}$ \\
Integration & $\begin{array}{l}\text { Students review and make a summary of what has been learned for the purpose of building a } \\
\text { new overview of a network of objects and establish the relationships among them. }\end{array}$ \\
\hline
\end{tabular}

Source: van Hiele (1999, p. 1-3)

Table 2

van Hiele's Levels of Geometric Thinking

\begin{tabular}{|c|c|}
\hline Level & Description \\
\hline $\begin{array}{l}\text { Recognition/ } \\
\text { Visualisation }\end{array}$ & $\begin{array}{l}\text { Students can learn names of figures and recognise a shape as a whole. Descriptions are } \\
\text { based purely on visual appeal. }\end{array}$ \\
\hline Analysis & $\begin{array}{l}\text { Students can identify properties of figures but they do not yet understand the } \\
\text { relationships between these properties and between different figures }\end{array}$ \\
\hline $\begin{array}{l}\text { Informal } \\
\text { Deduction }\end{array}$ & $\begin{array}{l}\text { Students can logically order figures and relationships, but not operate within a } \\
\text { mathematical system. }\end{array}$ \\
\hline
\end{tabular}

Source: van Hiele (1999, p. 316)

In this study, van Hiele's phases of learning and levels of geometric thinking were used as references for developing activities while the learning strategy adopted was based on constructivist approaches. Spatial visualisation oriented activities were adopted for use with the Google SketchUp (GSU). According to Noraini (2006), van Hiele's phases and levels of geometric thinking are appropriate as a basis in planning geometry learning activities.

In Phase III, activities based on van Hiele's phases of learning and levels of geometric thinking were developed. Constructivist approaches and activities that promote the formation of spatial visualisation ability were integrated with development of conceptual and procedural knowledge in the GSU environment. In this phase, the learning kits consist of modules developed as the experiment progresses until they were all completed. An overview of the processes involved in the development of the learning module is shown in Figure 1. It reflects the sequence and structure of the learning processes experienced by students. It also reflects how the user moves from one part of the developed learning environment to another part.

Based on the ADDIE model, Phase IV is the implementation phase which is the process of conducting the research. The assessments of activities were based on the phases of learning in the three modules. A pilot study was conducted using the learning materials that had been developed in order to get feedback from the experts and the target group. In addition, the validity and reliability of the instruments were also determined. In Phase $\mathrm{V}$, formative and summative evaluation from the experts and target group were conducted.

\section{METHOD}

True experiment was conducted to ascertain the research questions. This section discusses the entire methodology for the study. 


\section{Participants}

The participants were 96 elementary school students. Thirty-two of the students were randomly selected and assigned to the control group (NVH-CI) and there were 32 students each in the two treatment groups, group 1 (VH-PL) and group 2 (VH-GSU). Prior to that, Wu's Geometry Test was conducted and the scores were used to classify students into the three categories based on their performance. Random selection of research participants from each of the categories were then made to ensure that the three groups were equal based on students' levels of geometric thinking. The researcher also ensured that the number of male and female students in each of the groups was balanced.

\section{Instrument}

The van Hiele's's levels of geometric thinking were measured using Wu's Geometry Test (WGT) developed by Wu and Ma (2005). Several adaptations were made to the WGT in order to make it suitable for the content covered in this study as well as to reflect the Malaysian geometry curricular prescriptions. The adapted version of WGT comprises of 75 items to represent five geometry topics covered in the study and they were Triangles, Squares, Cubes, Rectangles and Cuboids. For each geometry topic, five items represented van Hiele's Level 0 (L0), Level 1 (L1) and Level 2 (L2) respectively. The WGT used van Hiele's Geometry Test (VHG) scoring principles originally set by Usiskin (1982). Thus, a student is considered to have achieved a particular van Hiele's level of geometric thinking if they managed to answer correctly at least three out of five items designated for that particular level. This would mean that the threshold percentage to progress from one level to the next would be at 60 percent. Table 3 showed the example of WGT in different levels.

Table 3

Example of Test Items of the Adapted Wu's Geometry Test

\begin{tabular}{l} 
Module \\
\hline 1
\end{tabular}

International Journal of Instruction, January2019 • Vol.12, No.1 


\section{Validity and Reliability of the Instrument}

Wu's Geometry Test (WGT) was given to three experts, that is, a teacher and two mathematics experts from a university to examine the suitability of all the items. The evaluation was on the format, meaning, language, font size, instruction given, spelling and, most importantly, the appropriateness of the item to the standard and level of difficulty for the purpose of study. The coverage of the five questions for each different shape at three different levels of geometric thinking made up a total of 75 questions. These questions underwent a pilot study to evaluate the difficulty and reliability. KuderRichardson Formula 20 (KR-20) was conducted to ensure the consistency of the Wu's Geometry Test (WGT). A coefficient of 0.70 was established. Thus, based on Fraenkel and Wallen (2003), the test was reliable since the coefficient was at least 0.70 .

\section{Experimental Procedure}

Once the participants of the instructional groups were identified, the experiment was conducted by the researcher for all the groups. The experiment for the technology assisted instructional group was conducted in the school computer laboratory, whilst the instruction for the other two groups were conducted in ordinary classrooms. To minimize interference with daily routines in the school, the experiment was conducted in the afternoon, after the school session ended. The researcher controlled all internal and external threats to the experimental study. Pre-test was administered during the first session after the explanation on what was required of their participation was given. The learning of geometry using the van Hiele's Phases Learning (VH-PL), van Hiele's Levels of Geometry Thinking using Google SketchUp (VH-GSU) and conventional teaching (VNH-CL) modules were carried out for eight sessions, conducted in a span of eight weeks with each session taking approximately 90 minutes.

The instructional materials such as the lesson plans for the two experimental and one control groups were prepared by the researcher. These lesson plans were used to ensure similarity in contents including examples across all three groups. The lessons were recorded and observed at random by an expert to ensure the equity of treatment in these three different groups. The modules were collected after each teaching session to ensure that they were not shared between the different groups of subjects.

In every two weeks, a different module was introduced and the unit test for the previous lesson was given. The post test was carried out during the last session, which is after eight weeks. A retention test was given a month after the treatment sessions.

\section{FINDINGS AND DISCUSSION}

All groups had an almost equal number of males and females. Altogether, there were 45 (46.9\%) males and $51(53.1 \%)$ females. All subjects involved in the study took the pretest to determine their van Hiele's levels of geometric thinking before they were randomly selected into three different groups. The distribution of participants in each of the three groups in terms of gender and van Hiele's levels of geometric thinking is portrayed in Table 4. 
Table 4

Profile of Respondents

\begin{tabular}{lcccc}
\hline & \multicolumn{4}{c}{ Demography } \\
\cline { 2 - 5 } Group & \multicolumn{2}{c}{ Frequency } & \multicolumn{2}{c}{ Percentage } \\
\hline NVH-CI Control & 15 & 17 & 15.63 & 17.70 \\
VH-PL Treatment 1 & 15 & 17 & 15.63 & 17.70 \\
VH-GSU Treatment 2 & 15 & 17 & 15.63 & 17.70 \\
\hline Total & 45 & 51 & 46.89 & 53.10 \\
\hline
\end{tabular}

The test scores gathered from the pre-test were analyzed using the methods and conventions mentioned earlier. Table 4 shows the summary of the van Hiele's levels of geometric thinking among the research participants before the intervention. Table 5 shows that during pre-test, all students achieved van Hiele's levels of geometric thinking of L2 and below with six of them in the 'lower than L0' (BL0) level. These six students were considered as those not meeting the van Hiele's requirements to learn geometry effectively. This showed that, before the intervention, most students only operated at the recognition (L0) (18.7\%) and analysis (L1) (71.9\%) levels.

This finding is similar with those found by Humphrey (2008) and Usiskin (1982). Humphrey (2008) conducted a study on 144 students from Nigeria and South Africa and found them at the range of pre-recognition level (BL0) and analysis level (L1). A similar finding was made by Usiskin (1982) who revealed in his study that the 2361 high school students were equal to or below the analysis level (L1) of van Hiele's levels of geometric thinking.

Table 5

Summary of van Hiele's Levels of Geometric Thinking among Students Before and After Intervention $(\mathrm{n}=96)$

\begin{tabular}{|c|c|c|c|c|c|}
\hline \multirow{2}{*}{ Group } & \multirow{2}{*}{ Level } & \multicolumn{2}{|l|}{ Pre-test } & \multicolumn{2}{|l|}{ Post-test } \\
\hline & & Number & Percentage & Number & Percentage \\
\hline \multirow{4}{*}{ NVH-CI } & L2 & 1 & 3.1 & 11 & 34.4 \\
\hline & L1 & 23 & 71.9 & 17 & 53.1 \\
\hline & LO & 6 & 18.7 & 3 & 9.4 \\
\hline & BL0 & 2 & 6.3 & 1 & 3.1 \\
\hline Mean Scores & & \multicolumn{2}{|c|}{60.3} & \multicolumn{2}{|c|}{67.7} \\
\hline \multirow{4}{*}{ VH-PL } & L2 & 1 & 3.1 & 17 & 53.1 \\
\hline & L1 & 23 & 71.9 & 14 & 43.8 \\
\hline & L0 & 6 & 18.7 & 1 & 3.1 \\
\hline & BL0 & 2 & 6.3 & 0 & 0 \\
\hline Mean Scores & & \multicolumn{2}{|c|}{57.8} & \multicolumn{2}{|c|}{67.6} \\
\hline \multirow{4}{*}{ VH-GSU } & L2 & 1 & 3.1 & 23 & 71.9 \\
\hline & L1 & 23 & 71.9 & 8 & 21.8 \\
\hline & L0 & 6 & 18.7 & 1 & 6.3 \\
\hline & BL0 & 2 & 6.3 & 0 & 0 \\
\hline Mean Scores & & \multicolumn{2}{|c|}{61.0} & \multicolumn{2}{|c|}{73.8} \\
\hline
\end{tabular}

Note: BLO refers to Below LO. 
Studies conducted by several researchers have also revealed phenomena which are more or less similar (Ding \& Jones, 2006; Noraini, 2007; Wu \& Ma, 2005). Their findings showed that the students in their studies only operated at the lower level of van Hiele's levels of geometric thinking.

After the intervention for the three different groups using the three different strategies, that is, using the van Hiele's Phases Learning Module (VH-PL), van Hiele's Levels of Geometric Thinking using Google SketchUp Module (VH-GSU) and Conventional Instruction strategy (NVH-CI), the results showed an improvement in all three groups. In the NVH-CI group, the number of students who progressed to the Informal Deduction level (L2) increased by 10 (31.3\%) students. However, in the VH-PL and VH-GSU groups, the number of students increased by $16(50 \%)$ and $22(68.8 \%)$ respectively. Thus, this suggested van Hiele's theory had been successful in helping students to progress to the higher van Hiele's levels in learning geometry.

This finding was similar to those carried out by researchers around the world who had successfully helped their learners improve in the learning of geometry (Abdul Halim, 2013; Ding \& Jones, 2006; Humphrey, 2008; Wu \& Ma, 2005). Learning geometry using van Hiele's theory had successfully eliminated students who were below the Visualisation level and had helped them to progress to at least Level 0 (Visualisation Level).

Table 6 shows the students' performance based on van Hiele's levels of geometric thinking before and after the intervention according to categories of progression (progress to next level, progress but stay in same level, no progression). Results showed that the students in the VH-GSU group showed very good performance and almost $94 \%$ of the students progressed to the next level. This was followed by those who used van Hiele's Phases learning strategy (VH-PL) and the lowest performance was recorded for those who followed the conventional learning (NVH-CI).

Table 6

Summary of Progressions of van Hiele's Levels of Geometric Thinking among Students' before and after using the Different Learning Modules

\begin{tabular}{llll}
\hline \multirow{2}{*}{ Group } & $\begin{array}{l}\text { Category of Progression of van Hiele's Levels } \\
\text { of Geometric Thinking }\end{array}$ & $\begin{array}{l}\text { Number of Students } \\
\text { (Percentage) }\end{array}$ \\
\hline \multirow{3}{*}{ NVH-CI } & Progress to next level & 15 & $(46.9)$ \\
& Progress but stay in same level & 13 & $(40.6)$ \\
& No Progression & 4 & $(12.5)$ \\
VH-PL & Progress to next level & 24 & $(75.0)$ \\
& Progress but stay in same level & 8 & $(25.0)$ \\
\multirow{2}{*}{ VH-GSU } & No Progression & 0 & $(0.0)$ \\
& Progress to next level & 30 & $(93.8)$ \\
& Progress but stay in same level & 2 & $(6.2)$ \\
\hline
\end{tabular}

Table 7 shows that the VH-GSU group had the highest increase in the number of students who progressed to the higher level when compared to the VH-PL group in which the number of students in Level 1 (Analysis Level) had seen a reduction in the 
number of students from $23(71.9 \%)$ in pre-test to $8(25.0 \%)$ in post-test while the VHPL group only reduced 9 (28.1\%) students. This information suggested that the VH-PL and VH-GSU Learning Modules had managed to assist students to progress through their first three van Hiele's levels of geometric thinking, with all of them managing to progress at least within the levels. Among them, more than half of them had progressed to higher levels. The mean scores increased from $57.8 \%$ to $67.6 \%$ and $61.0 \%$ to $73.8 \%$ respectively.

Table 7 also shows the comparison of the number of students and percentage according to their van Hiele's levels of geometric thinking in the pre-test, post-test and the retention test which was taken one month after the intervention. For the retention test, there were only six students at the level of Informal Deduction (L2) in the conventional group (NVH-CI) one month after the intervention. Earlier on in the post-test, 11 students were already at the L2 level and this showed a $15.7 \%$ decrease in the number of students. For the L1 level (Analysis), the number of students in the pre-test was almost equal to the number in the retention test. Only the visualisation level (LO) retained the number of students and there were two students who were still unable to achieve the visualisation level as in pre-test.

Table 7

Summary of Students' van Hiele's Levels of Geometric Thinking in Pre-test, Post-test and Retention Test $(\mathrm{n}=96)$

\begin{tabular}{|c|c|c|c|c|c|c|c|}
\hline \multirow{2}{*}{ Group } & \multirow{2}{*}{ Level } & \multicolumn{2}{|c|}{ Pre-test } & \multicolumn{2}{|c|}{ Post-test } & \multicolumn{2}{|c|}{ Retention Test } \\
\hline & & Number & Percentage & Number & Percentage & Number & Percentage \\
\hline & L2 & 1 & 3.1 & 11 & 34.4 & 6 & 18.7 \\
\hline NVH- & L1 & 23 & 71.9 & 17 & 53.1 & 21 & 65.6 \\
\hline \multirow[t]{2}{*}{ CI } & L0 & 6 & 18.7 & 3 & 9.4 & 3 & 9.4 \\
\hline & BL0 & 2 & 6.3 & 1 & 3.1 & 2 & 6.3 \\
\hline \multicolumn{2}{|c|}{ Mean Scores } & \multicolumn{2}{|c|}{60.3} & \multicolumn{2}{|c|}{67.7} & \multicolumn{2}{|c|}{67.1} \\
\hline \multirow{4}{*}{ VH-PL } & L2 & 1 & 3.1 & 17 & 53.1 & 13 & 40.6 \\
\hline & L1 & 23 & 71.9 & 14 & 43.8 & 18 & 56.3 \\
\hline & L0 & 6 & 18.7 & 1 & 3.1 & 1 & 3.1 \\
\hline & BL0 & 2 & 6.3 & 0 & 0 & 0 & 0 \\
\hline \multicolumn{2}{|c|}{ Mean Scores } & \multicolumn{2}{|c|}{57.8} & \multicolumn{2}{|c|}{67.6} & \multicolumn{2}{|c|}{67.8} \\
\hline & L2 & 1 & 3.1 & 23 & 71.9 & 23 & 71.9 \\
\hline VH- & L1 & 23 & 71.9 & 8 & 25.0 & 7 & 21.8 \\
\hline \multirow[t]{2}{*}{ GSU } & L0 & 6 & 18.7 & 1 & 3.1 & 2 & 6.3 \\
\hline & BL0 & 2 & 6.3 & 0 & 0 & 0 & 0 \\
\hline \multicolumn{2}{|c|}{ Mean Scores } & \multicolumn{2}{|c|}{61.0} & \multicolumn{2}{|c|}{73.8} & \multicolumn{2}{|c|}{72.2} \\
\hline
\end{tabular}

Note: $\quad$ BLO refers to Below LO.

The number of students dropping to the previous level in the VH-PL group was fewer than the number in the NVH-CI group. The students were $12.5 \%$ fewer in the Informal Deduction level (L2) after the retention test when compared to the post-test. The number of students in the Analysis level (L1) had increased to $18(56.3 \%)$ but it was still lesser than the number of students in the pre-test which was $23(71.9 \%)$ students. In the Visualisation level (L0), the number remained the same as there was only one student in 
this category. In the VH-GSU group, the number of students performing at the Informal Deduction level (L2) was the same in both the retention test and the post-test. There was only one student who fell back to the previous level (L0) during the retention test.

Table 8

Tests of between-Subjects Effects of van Hiele's Levels of Geometric Thinking in the Post test and Retention test

\begin{tabular}{ccccccc}
\hline Source & $\begin{array}{c}\text { Type III Sum of } \\
\text { Squares }\end{array}$ & df & $\begin{array}{c}\text { Mean } \\
\text { Square }\end{array}$ & F & Sig. & Partial Eta Squared \\
\hline Group & 512.767 & 2 & 256.384 & 6.290 & .003 & .121 \\
\hline
\end{tabular}

ANCOVA was used to evaluate the difference in the overall means of van Hiele's levels of geometric thinking in the post-test and retention test after one month of intervention, between students who underwent different strategies in the learning of geometry ( $\mathrm{VH}-$ GSU, VH-PL and NVH-CI) using pre-test scores as control. Table 8 shows that, in the post-test, there was a statistically significant difference in the van Hiele's levels of geometric thinking between the three different groups, $[F(2,91)=6.29, p<.05$, partial $\left.\eta^{2}=.121\right]$. Eta squared showed quite a large effect among the groups because it was close to 0.13 based on the guide by Cohen (1988). This suggested that there was a significant difference in the overall mean of van Hiele's levels of geometric thinking after test performance between students who underwent the different strategies in learning geometry (VH-GSU, VH-PL and NVH-CI).

Table 9

Pairwise Comparisons of van Hiele's Levels of Geometric Thinking in Post-test

\begin{tabular}{lcllc}
\hline \multicolumn{2}{c}{ (I) Groups } & & (J) Groups & Sig. $^{\text {b }^{2}}$ \\
\hline NVH-CI & $\mathrm{M}=68.55$ & VH-PL & $\mathrm{M}=67.63$ & .001 \\
& & VH-GSU & $\mathrm{M}=73.81$ & .000 \\
VH-PL & \multirow{3}{*}{$\mathrm{M}=67.63$} & NVH-CI & $\mathrm{M}=68.55$ & .001 \\
& & VH-GSU & $\mathrm{M}=73.81$ & .043 \\
VH-GSU & $\mathrm{M}=73.81$ & NVH-CI & $\mathrm{M}=68.55$ & .000 \\
& & VH-PL & $\mathrm{M}=67.63$ & .043 \\
\hline
\end{tabular}

Post hoc test shows that, using Bonfferoni adjustment, VH-GSU group ( $M=73.81, S D$ $=10.23$ ) is statistically significantly different (Table 9) when compared to VH-PL group $(M=67.63, S D=7.59)$ and NVH-CI group $(M=68.55, S D=10.02)$. Similarly, the VH-PL group $(M=67.63, S D=7.59)$ was significantly different when compared to the NVH-CI group $(M=68.55, S D=10.02)$ as well. These suggest that the teaching and learning strategies had a positive effect on the students in the VH-GSU and VH-PL groups. 
Table 10

Tests of Between-Subjects Effects of van Hiele's Levels of Geometric Thinking in the Retention-test

\begin{tabular}{ccccccc}
\hline & Type III Sum of & \multicolumn{3}{c}{ Mean } & Partial Eta \\
Source & Squares & df & Square & F & Sig. & Squared \\
\hline Group & 328.412 & 2 & 164.206 & 3.977 & .022 & .080 \\
\hline
\end{tabular}

Table 10 shows that there was a statistically significant difference in the retention test of van Hiele's levels of geometric thinking between the three different groups, $[F(2,91)=$ $3.98, p<.05$, partial $\left.\eta^{2}=.080\right]$. Partial eta squared showed a medium actual effect in the retention test among the three different groups based on the guide by Cohen (1988).

Post hoc test in Table 11 shows that the VH-GSU group $(M=72.19, S D=8.95)$ is statistically significantly different when compared to the NVH-CI group $(M=67.94, S D$ =9.78). Meanwhile, the VH-PL group $(M=67.75, S D=6.67)$ was not significantly different when compared to the VH-GSU group $(M=72.19, S D=8.95)$ and NVH-CI group $(M=67.94, S D=9.78)$. This suggests that only students in the VH-GSU group still showed a positive effect during the retention test.

Table 11

Pairwise Comparisons of van Hiele's Levels of Geometric Thinking in the Retention test

\begin{tabular}{lclcc}
\hline \multicolumn{2}{c}{ (I) Groups } & & (J) Groups & Sig. $^{\text {b }}$ \\
\hline NVH-CI & $\mathrm{M}=67.94$ & VH-PL & $\mathrm{M}=67.75$ & .465 \\
& & VH-GSU & $\mathrm{M}=72.19$ & .018 \\
VH-PL & \multirow{3}{*}{$\mathrm{M}=67.75$} & NVH-CI & $\mathrm{M}=67.94$ & .465 \\
& & VH-GSU & $\mathrm{M}=72.19$ & .536 \\
VH-GSU & $\mathrm{M}=72.19$ & NVH-CI & $\mathrm{M}=67.94$ & .018 \\
& & VH-PL & $\mathrm{M}=67.75$ & .536 \\
\hline
\end{tabular}

It must be noted that the VH-PL and VH-GSU learning modules were both designed to incorporate learning activities based on the application of van Hiele's theory. The difference was that the VH-GSU strategy utilized the advancement of computer technology. In particular, great emphasis had been given on the visualisation-based learning activities and hands-on explorations to develop geometry thinking that would actively engage the students in the learning processes and enhance students' conceptual understanding of geometry concepts. Bearing this in mind, the findings of this research seems to be consistent with those of Noraini's (2007) and Olkun's (2005). Both of them were using specially developed graphic software designed to assist students to learn geometry. In the study conducted by Noraini (2007), the effects of Geometer's Sketchpad on geometry achievement showed that there were significant differences between the control (traditional learning approach) and experimental (Geometer's Sketchpad) groups. She reported that the addition of dynamic geometry software in 
geometry construction had increased the students' interest in geometry as well as enhanced their understanding. In the case of Olkun (2005), Geometers' Sketchpad had been used to provide a suitable dynamic environment in which students could explore geometry according to their geometric thinking levels.

As a conclusion, students generally showed a more positive effect when the van Hiele's Levels of Geometric Thinking using Google SketchUp strategy (VH-GSU) was applied compared to the van Hiele's Phases Learning (VH-PL) strategy and the Conventional Instruction (NVH-CI) strategy. However, there was also a significant difference in the VH-PL strategy compared to the conventional teaching in practice. Therefore, the VHGSU module and VH-PL module were suitable in assisting students to progress in the van Hiele's levels of geometric thinking. After one month of intervention, the retention test showed that students in the VH-GSU group retained their learning better compared to the other two groups. Thus, the use of van Hiele's Levels of Geometric Thinking approach coupled with the use of the Google SketchUp promoted a better conceptual understanding and the students also managed to retain their understanding longer.

\section{CONCLUSION}

In this study, a preliminary analysis was carried out in the pre-test to identify students' van Hiele's levels of geometric thinking before the intervention. In most of the cases, the van Hiele's levels of geometric thinking among the students were found to be at a lower level before the use of VH-GSU and VH-PL learning modules. Most of the students seemed to be operating at the level of Recognition (L0) and managed to reach Analysis (L1) in the learning of geometry. These findings were more or less similar with those found by other researchers (Abdul Halim, 2013; Ding \& Jones, 2006; Gary, 2007; Mohd Salleh et al., 2012; Noraini, 2007; Humphrey, 2008; Usiskin, 1982; Wu \& Ma, 2005). The findings in this study concur with the findings by Noraini (2007) which suggested that a substantially large proportion of Malaysian elementary school children were operating at the lower levels of the van Hiele's levels of geometric thinking. This was similar to the levels of other school students in countries such as the United States, United Kingdom, China, and Taiwan. Nevertheless, the findings of the pre-tests had provided strong indications of the serious deficiencies pertaining to the nature of geometry learning among the students under investigation.

After the intervention, descriptive statistics of Wu's Geometry Test (WGT) showed that most of the students in all three groups achieved a higher level of van Hiele's geometric thinking. This study had provided evidence that the VH-GSU and VH-PL modules were better in assisting elementary students to progress through the first three levels of van Hiele's geometric thinking in the learning of geometry. The VH-GSU Module had managed to assist most of the students to progress through their van Hiele's levels of geometric thinking with an average of $93.8 \%$ of them progressing to the next level compared to the VH-PL module $(75.0 \%)$ and conventional teaching method $(46.9 \%)$. Among them, $100 \%$ had managed to obtain higher scores even though some of them were still at the same level as in pre-test. The students' mean scores increased after the use of the VH-GSU learning module. The findings had provided evidence that the GSU graphic software could be utilized to assist learners to progress through their van Hiele's 
levels of geometric thinking. It was clear that although the GSU was not designed specifically for the learning of geometry, it can be used to assist students to achieve higher van Hiele's levels of geometric thinking.

Attainment by those in VH-PL module was not as good as those using VH-GSU module, but it still showed better understanding and improvement of van Hiele's levels of thinking when compared with those taught using the conventional instruction. The VHPL module can be introduced to those schools that do not have internet or computer facilities.

The retention test that was carried out one month after the intervention period showed that most of the students in the VH-GSU group still remained in the higher level of van Hiele's model when compared to those in the VH-PL and NVH-CI groups. Repeated measures using ANCOVA showed that there was a significant difference between the pre-test and post-test scores in the three different groups. This meant that there was improvement or progression in all the three groups including the two treatment groups and the control group. However, after detailed analysis using ANCOVA, the treatment group of VH-GSU showed higher improvement when compared to the VH-PL group. The NVH-CI group had some progression after the intervention, but it showed that the conventional instruction strategy had a minor effect in assisting the students in progressing to the higher levels of van Hiele's levels of geometric thinking. The retention test also showed that a great number of students dropped back to the previous level as they had similar scores to that in the pre-test. This finding was similar to the findings by Abdul Halim (2012), Erdogan, Akkaya and Celebi Akkaya (2009), and Wu and Ma (2010) who found that the subjects in the conventional learning group did not show great improvements in van Hiele's levels of geometric thinking.

This phenomenon gives rise to several interesting points. Firstly, the deficiency of van Hiele's levels of geometric thinking appears to be global in nature across boundaries of educational practices and curriculum. This deficiency might have been the major contributing factor to the learning difficulties encountered by learners around the globe. Secondly, the deficiency may hold the key that explains why Malaysian lower secondary students have low performance in TIMSS and PISA assessment. It is noted that as far as the van Hiele's levels of geometric thinking is concerned, the higher thinking skills of decision making and integration with other mathematical concepts require the learners to reach L4 (Rigor). Thirdly, the findings of this study indicate that van Hiele's levels of geometric thinking is the way to assist students in learning geometry as previous studies have also proven on the effectiveness of van Hiele's geometrical thinking in enhancing students' understanding in geometry (Abdul Halim, 2013; Mohd. Salleh et al, 2012; Senk, 1989; Pierre van Hiele, 1999; Usiskin, 1982; Wu \& Ma, 2010).

\section{Implication towards Teaching and Learning}

This study provides guidance to teachers to diversify their teaching methods, especially in the teaching of geometry. The modules developed in this study can be used as a guide to teachers in developing activities according to van Hiele's levels of geometric thinking. Teachers may also use the set of developed modules which had been tested to 
be effective. Lastly, teachers are encouraged to explore the use of technology in the teaching of geometry.

\section{REFERENCES}

Abdul Halim, A. (2013). The development and effectiveness of van Hiele phases of learning geometry with generating conjecture learning strategy in the Geometer's Sketchpad environment. (Unpublished PhD. thesis). Universiti Kebangsaan Malaysia, Bangi.

Abdul Halim, A. \& Effandi, Z. (2013). Enhancing Students' Level of Geometric Thinking through van Hiele's Based Learning, Indian Journal of Science and Technology, 6, 4432-4446.

Chew, C. M. \& Lim, C. S. (2013). Enhancing Primary Pupils' Geometric Thinking through Phase-based Instruction Using the Geometer's Sketchpad. Asia Pacific Journal of Educators and Education, 28, 33-51.

Cohen, J. (1988). Statistical power for the behavioural sciences. Hillsdale, NJ: Erlbaum.

Ding, L. \& Jones, K. (2006). Teaching geometry in lower secondary school in Shanghai, China. In Proceedings of the British Society for Research into Learning Mathematics, 26, 41-46.

Erdogan, T.; Akkaya, R. \& Celebi Akkaya, S. (2009). The effect of the van Hiele model based instruction on the creative thinking levels of 6th grade primary school students. Educational Sciences: Theory and Practice, 9(1), 181-194.

Fuys, D.; Geddes, D. \& Tischler, R. (1988). The van Hiele model of thinking in geometry among adolescents. Journal for Research in Mathematics Education, 3,1-196.

Fraenkel, J. \& Wallen, N. (2003). How to design and evaluate research in education (5th ed.). New York, NY: Mc Graw Hill.

Gary, K. (2007). Investigating Shape and Space in Mathematics: A Case Study. South African Journal of Education, 27(1), 19-35.

Gutierrez, A.; Jaime, A. \& Fortuny, J. M. (1991). An alternative paradigm to evaluate the acquisition of the van Hiele levels. Journal for Research in Mathematics Education, 22(3), 237-251.

Gutiérrez, A. \& Jaime, A. (1995). Towards the design of a standard test for the assessment of the student's reasoning in geometry. In Proceedings of the 19th P.M.E. Mathematics Educations Conference 3, 3-11.

Gutiérrez, A. \& Jaime, A. (1998). On the assessment of the van Hiele levels of reasoning. Focus on Learning Problems in Mathematics, 20, 27-46.

Humphreys, G. \& Spratt, M. (2008). Many languages, many motivations: A study of Hong Kong students' motivation to learn different target languages. System, 36(2), 313335 . 
Mason, M. (1998). The van Hiele levels of geometric understanding. In The Professional Handbook for Teachers: Geometry Vol. 4. Boston, MA: McDougalLittell/Houghton-Mifflin.

Ministry of Education Malaysia. (2010). Sukatan pelajaran matematik KBSM. Kuala Lumpur, Malaysia: Curriculum Development Centre. (In Malay language)

Ministry of Education Malaysia. (2013). Malaysia Education Blueprint 2013-2025. Kuala Lumpur, Malaysia: Ministry of Education.

Ministry of Education of Taiwan (MET) (1993). Curriculum standards for national elementary school in Taiwan. Taipei, Taiwan: The Author. (In Chinese)

Ministry of Education of Taiwan (MET) (2000). Grade 1-9 curriculum provisional guidelines-Mathematics. Taipei, Taiwan: The Author. (In Chinese)

Ministry of Education of Taiwan (MET) (2003). Grade 1-9 curriculum guidelines Mathematics. Taipei, Taiwan: Author. (In Chinese)

Nolan, V. T. \& Swart, A. J. (2015). Undergraduate Student Perceptions Regarding the Use of Educational Technology - A Case Study in a Statistics Service Course, Eurasia Journal of Mathematics, Science \& Technology Education, 11(4), 817-825.

Mohd. Salleh, A.; Mohamad, B. A. \& Tan, T. H. (2012). Assisting primary school children to progress through their van Hiele's levels of geometry thinking Using Google SketchUp. Procedia-Social and Behavioral Sciences , 64, 75-84.

Noraini, I. (1998). Spatial visualisation, field dependence/independence, van Hiele level, and achievement in geometry: The influence of selected activities for middle school students. (Unpublished doctoral dissertation). The Ohio State University, Columbus, Ohio, United States.

Noraini, I. (2005). Spatial visualisation and geometry achievement of form two students. Jurnal Pendidikan, 25(1), 29-40.

Noraini, I. (2007). The effect of Geometers' Sketchpad on the performance in geometry of Malaysian students' achievement and van Hiele geometric thinking, Malaysian Journal of Mathematical Sciences, 1(2), 169-180.

Olkun, S.; Altun, A. \& Smith, G. (2005). Computers and 2D geometric learning of Turkish fourth and fifth graders. British Journal of Educational Technology, 36(2), 317326.

Schäfer, M. (2003). The impact of learners' spatial capacity and worldviews on their spatial conceptualisation: A case study. (Unpublished doctoral thesis). Curtin University of Technology, Perth, Autralia.

Senk, S. L. (1989). van Hiele levels and achievement in writing geometry proofs. Journal for Research in Mathematics Education, 20(3), 309-321. Doi:10.2307/749519

Škrbec, M. \& Čadež, T. H. (2015). Identifying and fostering higher levels of geometric 
thinking. Eurasia Journal of Mathematics, Science \& Technology Education, 11(3), 601-617.

Usiskin, Z. (1982). van Hiele levels and achievement in secondary school geometry: Cognitive development and achievement in secondary school geometry project. Chicago, IL: University of Chicago Press.

van Hiele, P. M. (1986). Structure and insight: A theory of mathematics education. Orlando, FL: Academic Press.

van Hiele, P. M. (1999). Developing geometric thinking through activities that begin with play. Teaching Children Mathematics, 5(6), 310 - 316.

Wong, P. H. (2014). Success factors of Taiwan in TIMSS mathematics assessment. International Journal of Education and Psychological Research, 3(3), 6-12.

Wu, D. B. \& Ma, H. L. (2005). A study of the developing procedure of the van Hiele geometry test for elementary school students. Paper presented in The Third East Asia Regional Conference on Mathematics Education (ICMI Regional Conference), Aug 712, 2005. Shanghei, Nanjing, and Hangzhou China.

Wu, D. B. \& Ma, H. L. (2010). Development of Wu-Ma test of the van Hiele levels of geometrical thinking based on grey relational analysis. In Proceedings of the 10th WSEAS International Conference on New Aspects of Signal Processing, Computational Geometry and Artificial Vision. Stevens Point, WI: WSEAS

Wu, D. B.; Lee, D. C.; Lin, S. H. \& Ma, H. L (2015). A study of van Hiele of geometric thinking among $1^{\text {st }}$ through $6^{\text {th }}$ graders. Eurasia Journal of Mathematics, Science and Technology Education, 11(5), 1181-1196. 